\title{
Correlation study between Interleukin-17 Gene Polymorphisms and risk of development of recurrent aphthous ulcer in Han Chinese Population
}

\section{Haidong Xiang}

The second hospital of Hebei medical university

\section{Dongmei Cheng}

The second hospital of Hebei medical university

Han Guo

The second hospital of Hebei medical university

\section{Yan Wang}

The second Hospital of Hebei Medical university

\section{Zhiyu Jia}

The second hospital of Hebei medical hospital

Qi Gao ( $\square$ gasqi689@163.com )

The second hospital of Hebei medical university https://orcid.org/0000-0002-4431-4461

\section{Research article}

Keywords: IL-17, rs763780, pro-inflammation, polymorphism, recurrent oral ulceration

Posted Date: July 29th, 2020

DOI: https://doi.org/10.21203/rs.3.rs-41582/v2

License: (c) (i) This work is licensed under a Creative Commons Attribution 4.0 International License. Read Full License 


\section{Abstract}

Objective

Interleukin-17 (IL-17) is a pleiotropic cytokine which plays important role in the inflammatory diseases.

Methods

Polymorphisms of IL-17A rs2275913 and IL17F rs763780 were measured in 125 RAU cases and 116 healthy controls. The polymerase chain reaction-restriction fragment length was measured. The genotype distribution and disease risk, and its' relationship with RAU severity was analyzed.

Results

RAU risk were related with polymorphism of IL-17 gene at rs2275913 site after adjusting BMI, sex, age, smoking and drinking status (AA vs. GG: odds ratio (OR), 1.624; 95\% confidence interval (CI), 1.1252.250; $P=0.030 ; A$ allele vs. $G$ allele: $O R, 1.192 ; P=0.037 ; 95 \% \mathrm{Cl}, 1.012-1.404 ;)$. In addition, the rs763780 variant genotypes (TC and $\mathrm{CC}$ ) and $\mathrm{C}$ allele also have higher relevance to RAU compared with subjects who bears the TT genotype (TC vs. TT, OR: 1.312; $\mathrm{P}=0.039 ; 95 \% \mathrm{Cl}: 1.017-1.692 ; \mathrm{CC}$ vs. TT, OR: 2.812, $\mathrm{P}=0.006,95 \% \mathrm{Cl}: 1.338-5.909 ; \mathrm{C}$ allele Vs. T allele, OR:1.413, $\mathrm{P}=0.002,95 \% \mathrm{Cl}: 1.141-1.751) . \mathrm{We}$ also found serum IL-17 levels were greatly higher in RAU patients compared with controls $(P=0.001)$, and serum IL17 concentration is correlated with IL17 polymorphism.

Conclusion

Our research showed polymorphisms of IL-17 gene might related to the high-risk of RAU occurrence.

\section{Introduction}

Recurrent aphthous ulcer (RAU) is also known as recurrent aphthous stomatitis, with characters of recurrent episodes of oral ulcers. Reports indicated that RAU affects about $20 \%$ of populations [1, 2]. The etiology of RAU is multifactorial, genetic, immune, nutritional, and microbial factors and local trauma might contribute to the occurrence. In addition, family history of RAU is confirmed to be a risk factor for RAU [3].

The etiology of RAU is not well demonstrated clearly, previous studies indicated that inflammatory factors play an key role in the development of RAU [4,5]. Borra et al revealed that cytokine genes in peripheral blood mononuclear cells, such as IL-2, TNF-a and IL-6, contribute to the development of RAU [6]. Other research indicated that IL-10 mRNA levels decreased in RAU patients, which suggests a failure of suppressing inflammatory reaction to oral mucosa in immune system [7].

So far, few studies reported the association between polymorphism of inflammatory genes and risk of RAU. The polymorphisms of IL-1ß -3954 C/T (rs1143634), IL-6-174G/C (rs1800795), IL-10-1082A/G 
(rs1800896), and IL-10-819C/T (rs1800871) have been reported correlated with risk of RAU in a Chinese population [1]. While no association study about IL-17 polymorphisms and RAU was reported.

IL 17 play an important role in innate and adaptive immune functions. Five identified receptors (IL-17 receptor $A$ to $E$ ) and six members (IL-17A-F) $[8,9]$ of IL 17 have been identified so far. Among them, IL-17A and IL-17F are mainly produced and secreted by T helper 17 (Th17) cells, and composed a unique lineage of $\mathrm{CD} 4^{+}$effector cells [10]. Currently, IL-17 was considered as one of pro-inflammatory cytokines, and IL17 could initiate the release of pro-inflammation cytokines and chemokines, , matrix metalloproteinases, and antimicrobial peptides from myeloid cells, mesenchymal cells and even epithelial cells [11]. Recently, IL-17 has emerged as an important driver of pathogenic inflammation, and is considered a key underlying element in the pathogenesis of autoimmune diseases such as systemic lupus erythematosus, membranous glomerulonephritis, and others $[12,13]$.

Compelling studies indicated that genetic polymorphisms of IL-17 are associated with the susceptibility of several immune-mediated diseases, including ulcerative colitis, systemic lupus erythematosus, membranous glomerulonephritis and rheumatoid arthritis [14-17]. So far, however, the relationship between IL-17 polymorphism and RAU has been rarely reported in the literature, as well as public available genetic database. Therefore we postulate that IL-17 is a possible susceptibility factor for RAU, and aim to explore the association between the IL-17 polymorphisms with risk of RAU in Chinese population. The polymorphisms of IL-17A rs2275913 and IL-17F rs763780 with the susceptibility factors of RAU were evaluated in our recruited subjects. This case-control study was designed to explore the relationship of these two SNPs with the morbidity and severity of RAU.

\section{Materials And Methods}

\section{Subjects}

A total of 125 patients who were diagnosed of ROU were enrolled. The diagnostic criteria were horizontal range of oral ulcer being covered with yellow pseudo membrane, surrounding hyperemia, and with central sag and obvious causalgia, ulcer having cyclicity and being self-limiting and being at differential phase. Inclusion criteria included: (1) $\geq 6$-month of regularly recurrent episodes of oral aphthous ulcer; (2) at least two ulcers per month within 6 months; (3) full blood count was normal with serum B12 within 200$900 \mathrm{ng} / \mathrm{l}$, red cell folate within $110-700 \mu \mathrm{g} / \mathrm{l}$ and serum ferritin within range of $20-400 \mu \mathrm{g} / \mathrm{l}$. Exclusion criteria included: (1) pregnant woman; (2) history of in which oral ulcer caused by systemic disease such as Behc, et's syndrome, coeliac disease, Crohn's disease, ulcerative colitis or AIDS; (3) combined medication with systemic steroids, immunomodulatory drugs or cytotoxics. 116 healthy control without ROU were recruited from individuals receiving routine check-up in our hospital. The subjects from control group was confirmed with no history of ROU and matched with cases group with sex and age. The gender and age distribution in the RAU and healthy control group were shown in Table 1. Informed consent was obtained from all subjects. The protocol of investigation was approved by the Ethics Committee of the second hospital of Hebei Medical University. 


\section{Sample collection}

A total of $10 \mathrm{ml}$ peripheral blood was collected into EDTA tube by venipuncture from each subject for DNA isolation. The biochemical, physiological and immune parameters from the serum were also examined.

\section{Genomic DNA isolation}

DNA Blood Mini Kit (QIAGEN, Hilden, Germany) was used for DNA extracted for genomic studies. $200 \mu \mathrm{L}$ of whole blood was used following the menu instructions. DNA concentration was measured by spectrophotometry (NanoDrop 2000, Thermo Scientific, CA, USA) and diluted to about $40 \mathrm{ng} / \mu \mathrm{L}$.

\section{DNA Sequencing Analysis}

IL-17 copies were measured by PCR through amplification. The used primers of polymorphisms were: rs2275913, forward 5'-ATTTCTGCCCTTCCCATTTT-3' and reverse 5'- CCAGGAGTCATCGTTGTTT-3'; rs763780, forward 5'-GCAGAGCACTGGGTAAGGAG-3' and reverse 5'-CTGCATCAATGCTCAAGGAA-3'. Sequencing was measured by a Bio-Informatic company (Life technology, Shang Hai, China).

\section{Serum IL-17A and IL-17F levels}

Total serum was separated from collected non-anticoagulant blood samples by centrifugation at 3,000 rpm for $10 \mathrm{~min}$ at $4^{\circ} \mathrm{C}$ after blood clotted. The concentrations of serum IL-17A and $\mathrm{F}$ were measured by sandwich ELISA (Abcam, CA, USA) following the menu's instructions.

\section{Statistics}

The clinical data were described as mean \pm standard deviation (SD) in each group and analyzed by Student's $t$-test. The genotype and allelic frequencies had been calculated by Hardy-Weinberg equilibrium (HWE) through an online calculator (http://www.oege.org/software/hardy-weinberg.html), and further by Chi-square test following Fisher's exact test. Odds ratio (OR) and 95\% confidence interval (Cl) were calculated to evaluate to association between the SNP and the ROU risk by SPSS 19.0 software (IBM SPSS, USA). Statistically significance threshold was set up as $P<0.05$.

\section{Results}

\section{Study participants}

125 Chinese patients with RAU (mean age \pm SD $=39.5 \pm 12.9$ years) were recruited, 62 was men and 63 was women, 6 were smokers. All subjects were assessed by an oral medicine specialist, the presence of aphthous ulcers were confirmed by them.

Blood samples were also obtained from 116 age and sex-matched healthy Chinese controls. Their RAU status confirmed by medical records and inquiries of patients, there is still possible that a small 
proportion subjects suffered from RAU. This might weaken the identified strength of associations. In our study, only six smokers were recruited to the patient group while 10 smokers were recruited in healthy control, which make it impossible to evaluate the effect of smoking on any gene associations.

The detailed demographic characteristics of the study population was listed in Table 1. Statistical analysis showed there was no significant difference in age, gender, BMI and smoking between the two groups, which indicated that enrolled subject from two groups matched in the current study. However, it seems that alcohol drinking could increase the risk of RAU occurrence $(P=0.032$, table 1$)$.

\section{A allele of rs2275913 and C allele of rs763780 raise the risk of RAU}

The distributions of each genotype and allele from SNP sites are shown in Table 2, and their distribution complied with Hardy-Weinberg equilibrium. As for the genotype and allele distribution in rs2275913, a significant difference was observed between healthy control and RAU patients (Table 2). In addition, AA genotype carrier had remarkably increased risks of RAU occurrence compared with genotype GG ( $P<$ 0.05). Moreover, A allele carrier had higher risk on RAU occurrence compared with $\mathrm{G}$ allele carriers (OR, $1.1192 ; 95 \% \mathrm{Cl}, 1.012-1.404 ; p=0.037)$. In addition, data from table 2 also indicated the AA genotype and $A$ allele were substantially distributed in female population $(P<0.05)$, instead of male sub-population $(p>0.05$, Table 2).

We also observed similar results about rs 763780 polymorphism. There was a significant difference in the genotype and allele frequencies between RAU patients and control subjects, as demonstrated in Table 2 . In addition, $\mathrm{C}$ allele rather than $\mathrm{T}$ allele increases the risk of developing RAU (Table 2). Furthermore, our study indicated that $C$ allele caused higher risk than in T allele in female subgroup $(P=0.004)$. However, in the male sub-population, the $\mathrm{CC}$ genotype did not cause significant change of RAU risk ratio, as well as $\mathrm{C}$ allele.

\section{IL-17 polymorphism is related to RAU severity}

RAU severity was evaluated based on number of lesions in one patient. In the current study, we classified into two sub-groups, less than three lesions and $\geq$ three lesions in RAU patients. The distribution of SNP among RAU severity was listed in Table 3 . Results showed there was a significant difference between all the genotypes and alleles in different severity-groups, which suggests that these two IL-17 polymorphisms are risk factors for RAU severity.

\section{Serum IL-17A/F levels are higher in RAU patients}

The average serum IL-17A concentration was $2.38 \pm 0.14 \mathrm{pg} / \mathrm{mL}$ and $4.31 \pm 0.27 \mathrm{pg} / \mathrm{mL}$ in healthy controls and RAU patients, respectively (Table 1). IL-17A serum levels in RAU patients were higher than healthy controls ( $P=0.0221$, Table 1$)$. The serum levels of IL-17F in RAU patients were significantly higher compared with healthy subjects $(P=0.0314$, Table 1$)$. Further, $f$ of in each genotype, there was significant difference of serum IL-17A and IL-17F concentration among all three genotypes about these two genic 
loci (Table 4), which indicated that A allele in rs2275913 and C allele in rs763780 possibly increased the IL17A and IL17F secretion respectively in RAU patients.

\section{Discussion}

Recent researches indicated that Th17 cells and IL-17/IL23 pathway play important roles in pathology of inflammation-related diseases [13]. Several meta-analysis demonbstrated the relationship between gene polymorphisms of IL-17A (rs2275913) and IL-17F (rs763780) and the pathogenesis of inflammatory diseases, including periodontitis, SLE, golomerulonephritis, rheumatoid arthritis (RA), and inflammatory bowel disease [12]. Research also reported polymorphism of IL17A (rs2275913) is associated with osteitis after the Bacillus Calmette-Guérin vaccination [18, 19], and a variant of IL17F (rs763780) may participate in the development of immune thrombocytopenia [20] and necrotizing enterocolitis [21]. All these researches indicate that IL17 polymorphisms are possibly associated with immune mediated diseases widely.

A previous studies indicated that increasing of IL-17 A/F are effective in the pathogenesis of minor aphthous, particularly in the ulcerative stage [22]. No study reported the relationship between rs2275913 and rs763780 with risk of RAU occurrence. Present study seems to be first research to investigate the involvement of IL-17 gene polymorphisms in RAU and their correlation with serum levels of IL-17A/F. So far, there is no enough evidence to demonstrate whether these two SNPs affect the serum content of IL$17 \mathrm{~A}$ and $\mathrm{F}$. From the data in table 4, these two SNPs possibly affect the serum concentration of IL-17A/F. An allele in rs2275913 and C allele in rs763780 possibly increased the plasma concentration of IL17A and IL $17 \mathrm{~F}$ respectively, which provides the explanation that these 2 alleles increase the risk of RAU (Table 2). Current results show that the polymorphism of IL-17A affects the risk of RAU. In addition, subjects bearing the rs2275913 A allele have higher risk of developing RAU compared with $\mathrm{G}$ allele carriers. Furthermore, rs763780 C allele, was also related to an increased risk of developing RAU greatly. Further evaluation of the effect of IL-17 polymorphisms on RAU occurrence ratio was separated by gender, and we also find increased risk ratio in both male and female patients' subgroups, but no statistical significance was found due to limited population, bigger population size is still need to revealed the indepth mechanisms of this correlation.

Higher average serum concentrations of IL17A/F have been found in RAU patients when it was compared with healthy controls. Analysis of inflammatory cells, such as Th17, some strongly positive IL- $17 \mathrm{~A}^{+}$cells ae seen in the vascularized superficial connective tissue of human oral mucosa, and aggravate RAU. Cytokine genes such as IL-17A/F are associated with development and function of Th17 cell. Therefore, IL17 polymorphism regulated Th17 cell population is another possible mechanism that involved in RAUassociated inflammatory response.

There are some other limitations except for the small sample size population in Our study. The population of study was confined to Han Chinese, the findings might not apply to other population. It would of great significance if RAU patient from other ethnic population is studied. In addition, we only investigated 2 
SNPs in the IL-17 gene. If more SNPs would be defined for the occurrence of RAU, it will also make our research more significance. More importantly, allele frequency differences between cases and controls after population stratification could cause spurious associations in disease studies due to systematic ancestry differences, and lead to artificial positive results [23]. Therefore, more detailed statistical analysis is necessary to make our conclusions more reliable.

In a summary, our results indicated that IL-17 functional polymorphisms are correlated with the occurrence risk of RAU significantly. The variant alleles rs2275913 AA and rs763780 CC might lead to the higher risk of RAU, elevated serum IL-17A/F levels, as well as increased severity. All these results inhibiting IL17A/F might be a effective strategy to prevent and treat RAU.

\section{Declarations}

\section{Ethics approval and consent to participate}

The protocol of study was approved by the Ethics Committee of the second hospital of Hebei Medical University.

\section{Consent for publication}

Informed consent was obtained from each patient for their medical data using and consent for publication.

\section{Availability of data and material}

The relevant raw data will be freely available to any scientist wishing to use them for non-commercial purposes, without breaching participant confidentiality.

\section{Competing interests}

None.

\section{Funding}

None.

\section{Authors' contributions}

Conception and design: Xiang HD and Gao Q; Acquisition of data, Xiang HD, Cheng DM, Gao H and Wang Y; Statistical analysis, Jai ZY.

\section{Acknowledgement}

None. 


\section{References}

1. Jing, C. and J.Q. Zhang, Association between interleukin gene polymorphisms and risk of recurrent oral ulceration. Genet Mol Res, 2015. 14(2): p. 6838-43.

2. Ruan, H.H., et al., Frequencies of abnormal humoral and cellular immune component levels in peripheral blood of patients with recurrent aphthous ulceration. J Dent Sci, 2018. 13(2): p. 124-130.

3. Natah, S.S., et al., Recurrent aphthous ulcers today: a review of the growing knowledge. Int J Oral Maxillofac Surg, 2004. 33(3): p. 221-34.

4. Li, X.Y. and Z.C. Zhang, Assessment of serum malondialdehyde, uric acid, and vitamins $C$ and $E$ levels in patients with recurrent aphthous stomatitis. J Dent Sci, 2016. 11(4): p. 401-404.

5. Almoznino, G., et al., Elevated serum IgE in recurrent aphthous stomatitis and associations with disease characteristics. Oral Dis, 2014. 20(4): p. 386-94.

6. Borra, R.C., et al., The Th1 /Th2 immune-type response of the recurrent aphthous ulceration analyzed by cDNA microarray. J Oral Pathol Med, 2004. 33(3): p. 140-6.

7. Lewkowicz, N., et al., Predominance of Type 1 cytokines and decreased number of CD4(+)CD25(+high) $T$ regulatory cells in peripheral blood of patients with recurrent aphthous ulcerations. Immunol Lett, 2005. 99(1): p. 57-62.

8. Kolls, J.K. and A. Linden, Interleukin-17 family members and inflammation. Immunity, 2004. 21(4): p. 467-76.

9. Kawaguchi, M., et al., IL-17 cytokine family. J Allergy Clin Immunol, 2004. 114(6): p. 1265-73; quiz 1274.

10. Rutitzky, L.I., J.R. Lopes da Rosa, and M.J. Stadecker, Severe CD4 T cell-mediated immunopathology in murine schistosomiasis is dependent on IL-12p40 and correlates with high levels of IL-17. J Immunol, 2005. 175(6): p. 3920-6.

11. Quan, Y., et al., Association between IL 17 polymorphisms and risk of cervical cancer in Chinese women. Clin Dev Immunol, 2012. 2012: p. 258293.

12. Eskandari-Nasab, E., M. Moghadampour, and A. Tahmasebi, Meta-Analysis of Risk Association Between Interleukin-17A and F Gene Polymorphisms and Inflammatory Diseases. J Interferon Cytokine Res, 2017. 37(4): p. 165-174.

13. Louahchi, S., et al., Association study of single nucleotide polymorphisms of IL23R and IL 17 in rheumatoid arthritis in the Algerian population. Acta Reumatol Port, 2016. 41(2): p. 151-7.

14. Nordang, G.B., et al., Association analysis of the interleukin $17 \mathrm{~A}$ gene in Caucasian rheumatoid arthritis patients from Norway and New Zealand. Rheumatology (Oxford), 2009. 48(4): p. 367-70.

15. Arisawa, T., et al., The influence of polymorphisms of interleukin-17A and interleukin-17F genes on the susceptibility to ulcerative colitis. J Clin Immunol, 2008. 28(1): p. 44-9.

16. Hou, C. and F. Yang, Interleukin-17A gene polymorphism is associated with susceptibility to gastric cancer. Int J Clin Exp Pathol, 2015. 8(6): p. 7378-84. 
17. Wang, L., et al., Association analysis of IL-17A and IL-17F polymorphisms in Chinese Han women with breast cancer. PLoS One, 2012. 7(3): p. e34400.

18. Poomarimuthu, M., et al., Association of IL 17 and IL23R gene polymorphisms with rheumatic heart disease in South Indian population. Immunol Invest, 2018: p. 1-11.

19. Liehu-Martiskainen, M., et al., Interleukin 17A gene polymorphism rs2275913 is associated with osteitis after the Bacillus Calmette-Guérin vaccination. Acta Paediatrica, 2017. 106(11): p. 18371841.

20. Tolba, F.M., et al., Assessment of IL-17F rs763780 gene polymorphism in immune thrombocytopenia. Blood Cells Mol Dis, 2019. 75: p. 20-25.

21. Tian, J., et al., Association of single nucleotide polymorphisms of IL23R and IL 17 with necrotizing enterocolitis in premature infants. Mol Cell Biochem, 2017. 430(1-2): p. 201-209.

22. Seifi, S., et al., Salivary VEGF-R3, TNF-a, TGF- $\beta$ and IL-17A/F Levels in Patients with Minor Aphthous. Research in Molecular Medicine, 2015. 3(4): p. 35-40.

23. Price, A.L., et al., Principal components analysis corrects for stratification in genome-wide association studies. Nature Genetics, 2006. 38: p. 904.

\section{Tables}

Table 1 Demographic characteristics of the study population.

\begin{tabular}{|c|c|c|c|}
\hline riables & Healthy control $(\mathrm{n}=116)$ & $\begin{array}{l}\text { RAU } \\
(\mathrm{n}=125)\end{array}$ & $P$ value \\
\hline e (mean \pm SD) & $38.3 \pm 12.6$ & $39.5 \pm 12.9$ & 0.234 \\
\hline $\mathrm{X}$ & & & 0.617 \\
\hline Male & 56 & 62 & \\
\hline Female & 60 & 63 & \\
\hline dy mass index $\left(\mathrm{kg} / \mathrm{m}^{2}\right)$ & $25.6 \pm 3.2$ & $26.0 \pm 3.9$ & 0.178 \\
\hline Yes & 10 & 6 & 0.321 \\
\hline No & 106 & 119 & \\
\hline inking & & & 0.032 \\
\hline Yes & 29 & 55 & \\
\hline No & 87 & 70 & \\
\hline umber of lesions & & & \\
\hline$<3$ lesions & & 74 & \\
\hline$\geq 3$ lesions & & 51 & \\
\hline -17A concentration $(x \pm S, p g / m L)$ & $2.38 \pm 0.14$ & $4.31 \pm 0.27$ & 0.0221 \\
\hline$-17 \mathrm{~F}$ concentration $(\mathrm{x} \pm \mathrm{S}, \mathrm{pg} / \mathrm{mL})$ & $104.5 \pm 13.6$ & $144.6 \pm 14.5$ & 0.0314 \\
\hline
\end{tabular}

Table 2 Distributions of IL-17 SNPs genotypes in each group and analyses of associations between these polymorphisms and RAU 


\begin{tabular}{|c|c|c|c|c|c|c|c|c|c|c|c|c|}
\hline \multirow[t]{2}{*}{ Genotype } & \multicolumn{4}{|c|}{ Overall $\square \mathrm{N} \square$} & \multicolumn{4}{|c|}{ Female (N) } & \multicolumn{4}{|c|}{ Male $(\mathrm{N})$} \\
\hline & control & RAU & OR $(95 \% \mathrm{CI})$ & $P$ & control & RAU & OR $(95 \%$ CI $)$ & $P$ & control & RAU & OR $(95 \% \mathrm{CI})$ & $P$ \\
\hline rs2275913 & 116 & 125 & & & 60 & 63 & & & 56 & 62 & & \\
\hline GG & 46 & 29 & 1.00 & 1.000 & 26 & 16 & 1.00 & 1.00 & 20 & 13 & 1.00 & 1.000 \\
\hline GA & 47 & 56 & $\begin{array}{l}1.890(1.032- \\
3.462)\end{array}$ & 0.048 & 23 & 30 & $\begin{array}{l}2.120(0.928- \\
4.843)\end{array}$ & 0.098 & 24 & 26 & $\begin{array}{l}1.669(0.683- \\
4.066)\end{array}$ & 0.273 \\
\hline AA & 23 & 40 & $\begin{array}{l}2.759(1.381- \\
5.512)\end{array}$ & 0.006 & 11 & 17 & $\begin{array}{l}2.511(0.941- \\
6.701)\end{array}$ & 0.088 & 12 & 23 & $\begin{array}{l}2.949(1.099- \\
7.914)\end{array}$ & 0.051 \\
\hline \multicolumn{13}{|l|}{ Allele } \\
\hline $\mathrm{G}$ & 139 & 114 & 1.00 & 1.000 & 75 & 62 & 1.00 & 1.00 & 64 & 52 & 1.00 & 1.000 \\
\hline $\mathrm{A}$ & 93 & 136 & $\begin{array}{l}1.783(1.242- \\
2.560)\end{array}$ & 0.002 & 45 & 64 & $\begin{array}{l}1.720(1.035- \\
2.861)\end{array}$ & 0.040 & 48 & 72 & $\begin{array}{l}1.846(1.101- \\
3.096)\end{array}$ & 0.026 \\
\hline \multicolumn{13}{|l|}{ rs763780 } \\
\hline $\mathrm{TT}$ & 82 & 67 & 1.00 & 1.000 & 43 & 32 & 1.00 & 1.000 & 39 & 35 & 1.00 & 1.000 \\
\hline $\mathrm{TC}$ & 31 & 48 & $\begin{array}{l}1.895(1.088- \\
3.301)\end{array}$ & 0.026 & 15 & 26 & $\begin{array}{l}2.329(1.064- \\
5.097)\end{array}$ & 0.051 & 16 & 22 & $\begin{array}{l}1.532(0.696- \\
3.373)\end{array}$ & 0.235 \\
\hline $\mathrm{CC}$ & 3 & 10 & $\begin{array}{l}4.080(1.079- \\
15.425)\end{array}$ & 0.040 & 2 & 5 & $\begin{array}{l}2.759(1.381- \\
5.512)\end{array}$ & 0.235 & 1 & 5 & $\begin{array}{l}5.571(0.620- \\
50.031)\end{array}$ & 0.201 \\
\hline \multicolumn{13}{|l|}{ Allele } \\
\hline $\mathrm{T}$ & 195 & 182 & 1.00 & 1.000 & 101 & 90 & 1.00 & 1.000 & 94 & 92 & 1.00 & 1.000 \\
\hline C & 37 & 68 & $\begin{array}{l}1.969(1.257- \\
3.083)\end{array}$ & 0.003 & 19 & 36 & $\begin{array}{l}2.126(1.139- \\
3.969)\end{array}$ & 0.021 & 18 & 32 & $\begin{array}{l}1.816(0.953- \\
3.462)\end{array}$ & 0.080 \\
\hline
\end{tabular}

RAU: recurrent aphthous ulcer; OR: odds ratio; CI: confidence interval

Table 3. The association of different genotypes and alleles of various polymorphisms with the severity of RAU.

\begin{tabular}{lllll}
\hline Genotype & $\mathrm{N}$ & $<3$ lesions & $\geq 3$ lesions & $P$ value \\
\hline rs2275913 & 125 & 74 & 51 & 0.003 \\
GG & 29 & 21 & 8 & \\
GA & 56 & 38 & 18 & \\
AA & 40 & 15 & 25 & \\
Allele & & & & 0.048 \\
G & 114 & 80 & 34 & \\
A & 136 & 78 & 58 & \\
rs763780 & 125 & 74 & 51 & $<0.001$ \\
TT & 67 & 51 & 16 & \\
TC & 48 & 20 & 28 & \\
CC & 10 & 3 & 7 & $<0.001$ \\
Allele & & & & \\
T & 182 & 122 & 60 & \\
C & 68 & 26 & 42 & \\
\hline
\end{tabular}

Table 4. The serum levels of IL-17A and IL-17F in the different genotypes in RAU patients

\begin{tabular}{lcc}
\hline Genotype & IL-17A $(\mathrm{x} \pm \mathrm{SD}, \mathrm{pg} / \mathrm{mL})$ & $\mathrm{IL}-17 \mathrm{~F}(\mathrm{x} \pm \mathrm{SD}, \mathrm{pg} / \mathrm{mL})$ \\
\hline rs2275913 & & \\
GG & $2.92 \pm 0.47$ & $119.9 \pm 21.6$ \\
GA & $3.61 \pm 0.33^{*}$ & $134.5 \pm 18.5^{*}$ \\
AA & $3.95 \pm 0.28^{* *}$ & $153.4 \pm 22.3^{*}$ \\
rs763780 & & \\
TT & $2.81 \pm 0.34$ & $108.3 \pm 23.4$ \\
TC & $3.72 \pm 0.28^{\#}$ & $142.1 \pm 22.1^{\#}$ \\
CC & $3.91 \pm 0.29^{\# \#}$ & $150.8 \pm 23.8^{\#}$ \\
\hline
\end{tabular}


*, $\mathrm{P}<0.05, * *, \mathrm{P}<0.01$, compared with GG genotype. \#, $\mathrm{P}<0.05$, \#\#, $\mathrm{P}<0.01$, compared with TT genotype. The significance was calculated by student's t-test. 